This item was submitted to Loughborough's Research Repository by the author.

Items in Figshare are protected by copyright, with all rights reserved, unless otherwise indicated.

\title{
"Are they just checking our obesity or what?": The healthism discourse and rural young women
}

\section{PLEASE CITE THE PUBLISHED VERSION}

PUBLISHER

(C) Routledge (Taylor \& Francis)

\section{VERSION}

AM (Accepted Manuscript)

\section{LICENCE}

CC BY-NC-ND 4.0

\section{REPOSITORY RECORD}

Lee, Jessica, and Doune Macdonald. 2019. "'are They Just Checking Our Obesity or What?": The Healthism Discourse and Rural Young Women". figshare. https://hdl.handle.net/2134/6500. 
This item was submitted to Loughborough's Institutional Repository (https://dspace.lboro.ac.uk/) by the author and is made available under the following Creative Commons Licence conditions.

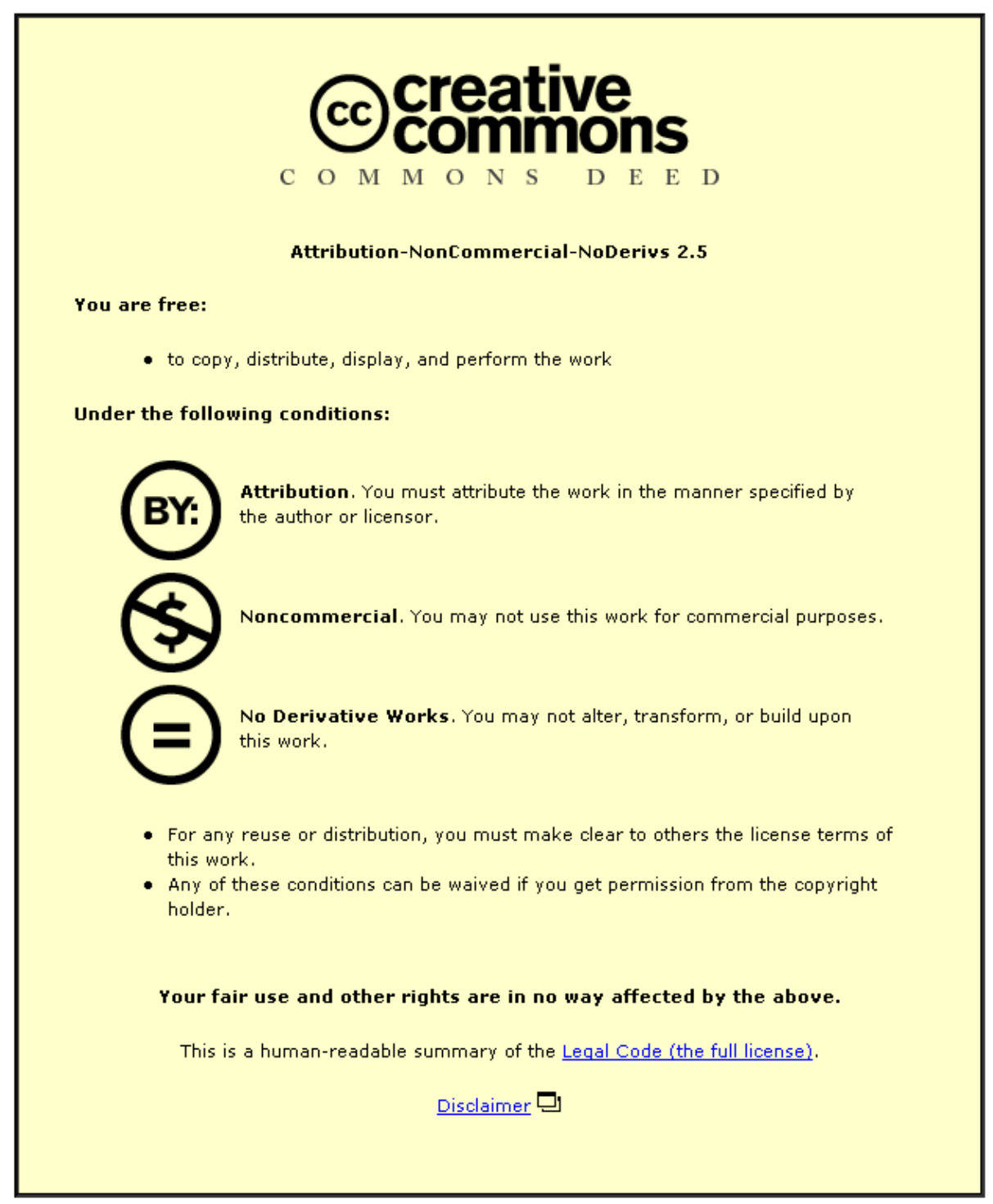

For the full text of this licence, please go to: http://creativecommons.org/licenses/by-nc-nd/2.5/ 
“Are they just checking our obesity or what?”: The healthism discourse and rural young women

Jessica Lee

School of Sport and Exercise Sciences, Loughborough University, UK

Doune Macdonald

School of Human Movement Studies, The University of Queensland, Australia

Correspondence:

Dr Jessica Lee

School of Sport and Exercise Sciences

Loughborough University

Leicestershire

LE11 3TU

UK

Tel:+44 (0)1509 223275

Fax: +44 (0)1509 226301

E-mail: j.lee2@lboro.ac.uk

Paper published in Sport, Education \& Society

Full reference: Lee, J. \& Macdonald, D. (2010). “Are they just checking our obesity or what?”: The healthism discourse and rural young women. Sport, Education and Society, 15 (2), 203-219. 


\begin{abstract}
This paper makes use of critical discourse analysis and Bourdieu's theoretical framework to explore rural young women's meanings of health and fitness and how the healthism discourse is perpetuated through their experiences in school physical education. The young women's own meanings are explored alongside interview data from their school physical education head of department. The healthism discourse was evident in the way that the young women spoke of physical activity, health, fitness and their bodies. They viewed health and fitness as being important to control body shape and adhered to a stereotypical feminine appearance as ideal. The data also illustrates how a school Health and Physical Education Head of Department's own engagements with the healthism discourse and the school's Health and Physical Education curriculum shaped the young women's understandings of health and fitness and their bodies. Data presented in this paper are drawn from an Australian longitudinal, qualitative project involving interview and visual collection methods. The longitudinal nature of the data adds to existing research by demonstrating the durability of the healthism discourse as it is perpetuated through physical education even up to two years postschool. Understanding how the healthism discourse is reproduced through social structures such as the school, and how it perpetuates traditional meanings and approaches to physical activity has important implications for the generation of physical activity and health promotion initiatives.
\end{abstract}

Keywords: health, fitness, rural, young women, healthism, Bourdieu, obesity 


\section{“Are they just checking our obesity or what?”: The healthism discourse and rural young women}

Public health messages around physical activity and fitness flood most contemporary forms of popular media and are indeed difficult to circumvent. Within these messages certain discourses concerning approaches to physical activity are circulated and perpetuated. These discourses and the ways of speaking within them shape behaviours and practices around physical activity which McGannon and Mauws (2002) argue is the product of "an historical acquisition of which people are usually unaware” (pp. 76-77). Therefore, to understand people’s engagements with physical activity, a mode of research that can account for this inculcation of history both within and around us is warranted (McGannon \& Mauws, 2002). Such a research agenda seeks to explore "the taken for granted terms and controversial accounts people make to themselves and others, and the implicit historical, social, and behavioural practices that reify and hold these in place” (McGannon \& Mauws , p. 81).

A growing number of researchers propose that while there are many discourses around health and fitness, the most dominant in the popular media and in health promotion is the healthism discourse. As such, throughout this paper we will refer to health and fitness discourses to connote the range of beliefs and messages around health and fitness and the healthism discourse as the dominant one within the range. The healthism discourse suggests that health can be achieved "unproblematically through individual effort and discipline, directed mainly at regulating the size and shape of the body” (Crawford, cited in Kirk \& Colquhoun, 1989, p. 149). In this way, the healthism discourse and obesity discourse are interrelated, such that the individualising responsibility for one's own health (and body shape/size) characterises the overweight or obese as lazy, self indulgent and greedy (Rich \& Evans, 2005). Public discourse around an 'obesity crisis’ is therefore justified within the healthism discourse as "individuals are deemed largely responsible for their own health and for making healthy choices” (Rich and Evans, 2005, p. 352). The notion of healthism forms the 
basis for a growing number of researchers who oppose the dominance of obesity discourses in public health, popular media, and schools (e.g. Aphramor, 2005; Burns, 1993; Evans, 2004; Evans, Rich \& Allwood, 2008; Gard \& Wright, 2001; Monaghan, 2005; Rich \& Evans, 2005; Wright, O’Flynn \& Macdonald, 2006). Such research argues that the idealisation of slim bodies and the individualistic conception that health can be sustained and illness prevented through the sheer effort of will and determination of individuals (Kirk \& Colquhoun, 1989) can actually instigate unhealthy orientations to the body and ideas of what constitutes healthy physical activity and diet. Throughout this paper, obesity discourse will therefore be discussed as part of the healthism discourse.

The harmful nature of this discourse in school Physical Education (PE) curriculum in New Zealand has been reported, such that young people uncritically linked body shape to health and fitness (Burrows, Wright \& Jungersen-Smith, 2002; Wright \& Burrows, 2004). Perhaps what is of more concern is that the young people took up the moralistic position which suggests that bodies that do not conform to the slim ideal are "unworthy, undisciplined, lazy, a couch potato" (Burrows et al., 2002, p. 46). These findings prompted the call for physical educators to examine their practices and curriculum which reproduce social meanings for students in the form of the healthism discourse, which "contribute to the anxieties and damaging practices associated with the desire to achieve a socially desirable body shape” (Burrows et al., 2002, p. 47).

The aim of this paper is to explore the healthism discourse within the sport and physical activity field and particularly, how it is perpetuated by schooling practices and taken up by a sample of rural young women and how it shapes, and is shaped by, the habitus. The rural young women and their school Physical Education teacher were participants in a larger longitudinal qualitative project interested in exploring young people's meanings of, and experiences with, physical activity and physical culture. This paper seeks to explore how dominant health promotion messages are taken up and/or challenged by young people and perpetuated through school practices in the context of a 
rural setting. In Australia in particular, rural young people have become a population of interest in physical activity and health promotion and are seen to be subject to what is being depicted as a 'rural health crisis'. Statistical reports suggest rural Australia has high rates of unemployment, underemployment, poverty and limited economic growth (Haberkorn, Kelson, Tottenham \& Magpantay, 2004; Strong, Trickett, Titulaer \& Bhatia, 1998). These factors combined result in what has been reported as poor health and education services for young people. These representations of rural Australia are in contrast to traditional notions of the Australian "outback” as a rural idyll populated by the fit and healthy "bronzed Aussies”. Most recently, the focus on rural health in Australia has been on levels of obesity, particularly in the popular media with headlines such as, “Rural areas hit hard by obesity” (Herald Sun, August 5, 2007), “Obesity 'as bad in the bush”” (ABC News, August 5, 2007) and "Growing concern for fat of the land” (The Australian, August 6, 2007). It is timely therefore, to explore how these messages are perpetuated in these settings and taken up by rural young people themselves.

The current research moves towards addressing Wright and Burrows’ (2004) call for further research into how young people make sense of the diverse and often contradictory ways in which health is represented to them. Where previous research has focussed either on young people's accounts of their experiences of school PE (e.g. Burrows et al., 2002; Evans et al., 2008) or teachers’ accounts of school practices (e.g. Kirk \& Colquhoun, 1989; Webb, Quennerstedt and Ohman, 2008), this study presents data from both the teacher's and students’ perspectives and demonstrates how the healthism discourse is embedded in teacher personal beliefs and subsequently perpetuated in their teaching practices and reproduced by the young people. As suggested by Luke (1996), Bourdieu's concepts of linguistic habitus and linguistic markets will be used to theorise how power and capital are associated with the healthism discourse, and how the discourse is perpetuated through schooling practices. 


\section{Research Method}

\section{Participants and locations}

Participants were from an Australian, longitudinal, qualitative study, The Life Activity Project ${ }^{1}$ (LAP) (see Wright et al., 2003; Wright et al., 2006). The data is drawn from case studies of five young women who attended Greenvalley High, a government secondary school in the rural town of Greenvalley (all names of people and locations have been substituted with pseudonyms). Greenvalley is a small town (approximately 1700 people) for which facilities and transport to surrounding locations is limited. While distance to a regional centre is not great, the services and facilities available are not easily accessible to the young people of Greenvalley due to the lack of public transport and service links. Greenvalley High has a relatively large student population (700) as it caters for many surrounding satellite towns and farming properties. The participants' home locations ranged from residential blocks within Greenvalley or satellite towns up to 25 kilometres from Greenvalley, and smaller properties within 20 kilometres of Greenvalley. The PE Head of Department (HoD) at Greenvalley High was also interviewed.

\section{Data collection and analysis}

The data presented in this paper were collected over three years through a series of in-depth interviews as part of the LAP. Each young person was interviewed two to three times per year. Interviews were conducted one-on-one and face-to-face and the young people chose locations that suited them (e.g. home, workplace, cafeteria). Broad interview topics included current and past physical activity experiences, physical culture (e.g. the body in the media, sports clothing, Olympics), locations, and health and fitness. For the current analysis most data was drawn from the health and fitness related interviews, however given the longitudinal nature of the project, other relevant data from interviews is included. 
All interviews were transcribed verbatim and stored in the NVivo programme which was used to sort the text into themes and search for recurring patterns of words, ideas, or ways of speaking. Discourse in this sense, including the healthism discourse, is understood as "sets of socially and historically constructed rules designating 'what is' and 'what is not'” (Taylor, 2000, p. 317). Critical discourse analysis (CDA) was used to examine how the healthism discourse was utilised and perpetuated for the rural young women by identifying the ways they understood and described health, fitness and physical activity and their adherences to the tenets of the healthism discourse. Their talk was then further examined for ways in which their understandings or actions were constrained or facilitated by their observances of the healthism discourse. During the data analysis process, particular attention was paid to the words the rural young people used to label forms of physical activity and the repetition and consistency of their use of certain discourses. This involved identifying patterns of speech and recurring use of words/phrases demonstrating reproduction of hegemonic beliefs around physical activity and health. Following Luke (1996), CDA was used to investigate how the young women's reproductions of the healthism discourse was affiliated with differing kinds of cultural capital and social power. CDA allowed for an exploration of how culture, gender, and location shaped the young people’s conceptions of physical activity and health.

While this study is positioned within the poststructural theoretical perspective because of its emphasis on discourse and power, a focus on the wider structural and institutional processes which impact on rural young people’s lives remains. Specifically, in terms of this study it is implied that rural young people are actively involved in negotiating a physical activity identity however, there remains significant evidence to suggest that their lives continue to be constrained by very real, material limits and lack of opportunities. In this way, Bourdieu's work building upon notions of structure and agency is useful in theorising the current findings. In particular, Bourdieu's notion of linguistic markets is useful in the exploration of the poststructuralist view that discourse is central to 
the understanding of social relations (Luke, 1997). Luke (1996) suggested historical production and reproduction of discourses in a field to “develop coherent explanations of the interrelationship among discourse, its ‘uptake’ in subjectivity, and 'bodily habitus’” (p. 39).

In Bourdieu’s study of language he rejected the Sassurian linguistic model as it "bracket[s] out the social, which allows language... to be treated like an end in itself” (Bourdieu, 1991, p. 34). Instead he proposed that relations of linguistic communication are "relations of symbolic power in which the power relations between speakers or their respective groups are actualized” (1991, p. 37). To understand the power relations in discourse, Bourdieu proposed the notions of linguistic habitus and the linguistic market. He defined the linguistic habitus as, "socially constructed dispositions... which imply a certain propensity to speak and to say determinate things (the expressive interest)... and the social capacity to use this competence adequately in a determinate situation” (Bourdieu, 1991, p. 37). The linguistic market is a concept that allows for the exploration of how discourses become dominant within a field and how the domination is "reproduced by institutions capable of imposing universal recognition of the dominant language” (Bourdieu, 1991, p. 40).

The linguistic habitus provides a means for understanding the inculcation of discourses from the social world. Bourdieu (1989) stated, "not all linguistic utterances are equally acceptable” and it is the linguistic market that determines "the price of linguistic products" (p. 47). Any linguistic exchange is the product of the encounter between a linguistic habitus and a market (Bourdieu, 1989) in the sense that any statement (a product of the linguistic habitus) can take the form of either the dominant discourse or a dominated discourse determined by the value it represents on the linguistic market. Bourdieu (1991) notes, "What circulates on the linguistic market is not 'language' as such, but rather discourses that are stylistically marked both in their production... and in their reception” (p. 39). 
While Bourdieu's framework has been rarely used as a tool for CDA, his concept of the habitus with its focus on the embodiment of the social world is of particular use when exploring the healthism discourse which is mostly concerned with the size and shape of the body. Bourdieu's notion of physical capital (extended by Shilling, 2003) allows for an examination of the body as “a possessor of power, status and distinctive symbolic forms which is integral to the accumulation of various resources” (Shilling, 2003, p. 111). Shilling describes the production and conversion of physical capital as follows,

The production of physical capital refers to the development of bodies in ways which are recognised as possessing value in social fields, while the conversion of physical capital refers to the translation of bodily participation in work, leisure and other fields into different forms of capital.

Bourdieu's concept of field is also particularly useful as it considers actions and power as situated and contextualised within a specific setting. Therefore, in the current study we can understand the circulation of the healthism discourse alongside other central discourses in the rural setting such as traditional gender roles and the dominance of physical labour (Lee \& Macdonald, 2009).

The healthism discourse, "driven by the interests of business and the economy and informed by the bio-sciences and psychological theories and practices” (Evans \& Davies, 2004, p. 40), has become dominant in the sport and physical activity field. A more in depth historical investigation into how this came to be the case is provided by Kirk and Colquhoun (1989) and Gard and Wright (2001). However, the important point here is that healthism is a legitimised discourse in the physical activity field and its use involves relations of power and linguistic domination consistent with Bourdieu’s (1989) statement, “linguistic relations are always relations of power” (p. 46). 


\section{The healthism discourse and rural young women}

This section explores the ways in which the rural young women took up the healthism discourse. Their conceptions of health and fitness were mainly homogenous, generally focussing on diet and exercise for the purpose of controlling body shape. In the following excerpts certain words or phrases demonstrating reproduction of the healthism discourse are shown in italics.

Jacinta: Healthy meaning eating right and doing a regular amount of sports or exercise pretty much.

Sally: Healthy [means], a lot of exercise, eating good, that's about all...

Int.: [Later in the same interview] Why do you think it's important to do more exercise? Sally: So you don't get fat...

Sally: [Later in the same interview] What is being fit? Umm a lot of exercise, do a lot of exercise a day, that's being fit...

Int.: Why is it important to be fit?

Sally: So you look good, that you look good.

Int.: What then, what do you mean by looking good?

Sally: Not being like big with all these rolls on ya [laughing]. Just looking slim, looking healthy.

Int.: Why are you not happy with your fitness level?

Sally: Because I'm feeling a bit big...

Tammy: Fit is more exercise orientated, muscle tone... Int.: Is being fit important to you? 
Tammy: No, only image wise, I don't want to be fat.

Int.: What does 'fit' or 'fitness' mean to you?

Sharon: Just exercising and just doing sporting things.

Int.: How can you tell if someone is fit?

Sharon: They just look it, they look really healthy and glowing and muscles, toned...

Int.: Why is it important (to be fit)?

Sharon: Because it makes your body look better to be toned.

The terminology that most of the young women used around sport and exercise, as opposed to physical activity, highlights the restrictive view of what they considered to be health enhancing physical activity. This is an important point within the rural context given the lack of formal exercise/sporting facilities available in small towns, particularly for the young women, resulting in the predominance of informal leisure time pursuits (e.g. push-bike riding, outdoor play with siblings), walking for transport, and physical labour (see Lee \& Macdonald, 2009 for further discussion of this point). Hence, the types of physical activities that these young women participated in were not seen as legitimate within their meanings of health and fitness. From the healthism discourse perspective therefore, they perceive themselves as not taking responsibility for their own health and fitness. Furthermore, they would also be perceived in the same light from a physical activity and health promotion angle. It is also noteworthy that at the time of these interviews only Tammy was still attending school (year 11), Sally and Jacinta had left school to move into employment and Sharon had finished school and had been working full-time for almost two years (see further discussion of this point in the following sections).

Despite the uniformity of the young women's understandings of health and fitness, there was some evidence of resistance where one young woman's meanings were broader as she mentioned absence of illness and mental health as elements of being healthy. 
Cassie: Pretty much being fit physically and mentally I suppose 'cause healthy is not just not being sick, it's being able to cope with pretty much every day things like strains that get put on you.

Int.: Is being healthy important to you?

Cassie: Yep, it has to be in my, where I, in my line of work [childcare] 'cause if I'm unfit or if I'm unable to deal with the children then I can't work pretty much.

Although Cassie's notion of health and fitness also focussed on the importance of work, her actions within the field were consistent with gender stereotypes as she spoke on different occasions about her body shape and "losing her tummy".

Cassie: I suppose I'm not really chubby but I'm not, I'm just over average weight so... That's just going on height to weight ratios like the doctor set out, for my height, I'm overweight...

For these young women their focus on the importance of physical appearance within health and fitness was evident. Their quotes on the body and "looking good" substantiate Crawford's (cited in Kirk and Colquhoun, 1989) claim that body shape is a corporeal metaphor for health. The following quote from Sharon highlights that the way a person looks or the shape of their body can indicate how fit or healthy they are.

Sharon: I'm not fat but I'd like to be a bit thinner... 'Cause you feel better when you're you know, nice and thin and your belly comes in and your butt's tiny and you feel heaps better. 
Sally linked appearance or "looking good" to health and fitness the most vehemently of all the young women. Not only was being fit and healthy important so that “you don't get fat” and "so you look good”, looking fit and healthy carried great importance to gain the respect of others.

Int.: So by looking good what do you mean?

Sally: Looking healthy, fit like muscley kind of, like not real muscley but you can see a bit muscley.

I: So is the way that you look important to you?

S: Yep, I think it is. It's important how I look [pause] so I don't [pause] ... It is important because you don't want to walk down the street and people look at you and you don't look very nice. You like to walk down the street and a couple of people whistle at you. Like you don't want it all the time but it's just nice. Shane [boyfriend] gets that a lot.

I: Do people whistle at him?

S: Yes... he loves it. He's like [holding head high] you know. But yeah it's important for me and for him as well like 'cause he's good looking and he doesn't want to be walking down the street with a feral [laughing], but I think it's important for me and my family.

This strong passage indicates that for Sally looking fit and healthy was important to gain respect from others and to uphold integrity for her family and her boyfriend. Sally’s comments demonstrate the moral imperative that underpins the healthism discourse which proposes that it is not just unhealthy to be fat but it is also wrong (Kirk \& Colquhoun, 1989).

The ideal physical appearance for displaying fitness and health, for a woman, was unanimously described by the rural young women as being thin with muscle tone but not too muscley, as muscle bulk was associated with masculinity. As Rich and Evans (2005) suggest, the healthism discourse normalises one particular body shape. Pictures of women, athletes and models, in a Women in Sport 
magazine stimulated discussion about women's bodies. The following comments relate to particular photos of an athlete (shown in Figure 1) from the Women in Sport magazine (Deutsher \& Carr, 2000).

Int.: What did you think of her in this picture?

Cassie: She's too muscley for that outfit, she looks out of place... she just looks out of proportion.

Sharon: She is so fit...[but] Yeah she shouldn't wear that, it makes her look like a bloke dressed up as a woman 'cause she's so muscley... She has nice legs, she could wear a skirt but don't show all that [indicating torso].

I: 'Cause it's just too muscley?

S: Yeah.

I: What about in her running outfit?

S: Yeah that looks okay. She looks like a bloke though.

I: She still looks like a man?

S: Yeah because of the muscles and her face, she has a hat on and it looks like a bloke.

\section{INSERT FIGURE 1 ABOUT HERE}

Tammy’s comments about the same picture mirror the views of the other girls i.e., that the woman is too muscley and is therefore not "normal”.

Tammy: She's got a good figure but for someone normal it's a bit too muscley but for what she's doing it's sort of right for you to have. 
However, later in the same interview when looking at an advertisement picturing female models, Tammy appeared to be trying to challenge the dominant discourse she had reflected earlier.

Tammy: Yeah, I don't, I'm not sure if it's the right thing, to be placing an ad if they're targeting young people, for younger women.

Int.: So what sort of thing did it say in the ads?

T: I don't know [I] basically looked at the pictures and thought it's probably not the best thing for young women even if they are trying to improve their figure it's really not the best thing to show.

I: Why do you think that?

T: [pause] Just like the way that they portray the women.

I: So do they look too thin?

T: Yeah sort of [pause] like where it says "Transfigure: for the ultimate butt and thighs". That isn't perfect, there is no "ultimate", everyone's different and to say that that is the right thing to have, I just think is not right.

The discourse of the lean, toned, fit, healthy, feminine body was so strong that Tammy struggled to maintain her stance of challenger or outsider to the discourse. The next quote shows how Tammy began to habitually reproduce the discourse then caught herself referring to the lean, toned models as "better” and quickly corrected herself.

Int.: Which women in the magazines were more real for you?

Tammy: Probably the ones in Chick [magazine] just seemed more average and the people in the Women in Sport [magazine] were obviously more fitness oriented so they were going to have better fig[stops mid-word], well not better that's a stereotype again, more muscley figures but leaner, things like that. 
The young women's linguistic habitus has been shaped by the healthism discourse so that it is reproduced with ease and consistency in response to a number of questions.

The young women's emphasis on the legitimised feminine body is also consistent with traditional gender stereotypes manifested in the gendered division of labour. In terms of the power relationship within the healthism discourse, this places the rural young women in a subordinate position in relation to rural young men (see author, 2009 for further exploration of rural young men and women) as it restricts the amount and type of physical activity that the young women have access to. As Gorely, Holroyd and Kirk (2003) point out, "If they [young women] conform to dominant forms of femininity, they are unlikely to play sport at all, or if they do, they are most likely to participate in traditionally ‘female’ activities” (p. 435).

Bourdieu's (1978) concept of physical capital is useful in identifying the resources available to the gender groups that determine their motility within the sport and physical activity field (Gorely et al., 2003). Although the young women felt that physical activity was important for maintaining slender and toned figures, "too much” muscle was considered to be masculine. This is consistent with Gorely et al.'s (2003) research on muscularity and the habitus with English young people. As muscular bodies were seen as masculine and therefore inappropriate, the physical capital (i.e. muscular bodies) available from participation in "too much" and certain kinds of physical activities and physical labour has little exchange value for the rural young women (see Lee \& Macdonald, 2009). While thinness could be perceived as a desirable outcome of participation in physical activity for the young women, it did not fuel a commitment to purposeful, regular physical activity. Dieting seemed to be the preferred mechanism for weight control, while physical activity as the young women perceived it (sports and exercise) was associated with muscular bodies. As such, the ways in which the rural young women engaged with the healthism discourse holds a lesser value on 
the linguistic market and are placed in a subordinate position of power given their limited exchange value of physical capital.

Reproduction of the healthism discourse: The school as a site of learning about health \& fitness The reproduction of the healthism discourse, was revealed through an examination of sites of learning. This required an analysis of how the particular linguistic habitus was formed in relation to the discourses to which individuals had been exposed. The web of historical power relations brought into play in even the simplest linguistic exchanges (Bourdieu, 1989) is the result of the reproduction of legitimised discourses acquired through "familiarization, that is, by more or less prolonged exposure to the legitimate language, or through the deliberate inculcation of explicit rules...” (Bourdieu, 1991). Bourdieu went on to identify the two principal sites for the reproduction of dominant discourses as the family and the educational system which directly coincide with data from this project. While parents were identified by most of the participants as sources of knowledge around health and fitness, the importance of family has been discussed in relation to this cohort elsewhere (authors, 2009; Wright et al., 2003). The focus of the data presented here is on the role of PE within the school in perpetuating the healthism discourse.

All of the young women cited the school as a site of learning about health and fitness. Tammy's comments below clearly outline the impact of the school, and in particular, their experiences in PE.

Int.: Where do you think you've learnt about health and fitness?

Tammy: School, they drum it into us I swear. No, 'cause you have to do HPE, like Health and Phys Ed... and they just run and stuff, like what is the point of sprinting just to check your time against someone else's?

Int.: Do they do that a lot, check your fitness and stuff? 
Tammy: Yeah, I don't understand why. Are they just checking our obesity or what? Like as a state, you know a nation wide survey [they] forced us to do it.

Int.: Anything about health and fitness from your parents at all?

Tammy: No, not really.

Int.: So what sort of things did you learn at school... what sort of things about health and fitness? What were the messages?

Tammy: At school it was more health like physically, like as in you'll be happier, you'll have more energy, you can do this and that, otherwise you'll be fat.

Sally also specified school as her main site of learning about health and fitness. Furthermore, both Tammy and Sally spoke unfavourably about being weighed and fitness testing such as running and sit-ups. School PE (called HPE [Health and Physical Education] in the compulsory years) lessons appeared to play a role in the linking of physical activity, health, and physical appearance/body shape.

Sally: I learnt health mainly at school. I did school health.

Int.: And what sort of things did they say about health?

Sally: Well we went to like Health and Phys Ed, HPE, that was like a lot of running around and they used to check our weight and sit-ups and how many you can do and that for our health... we did that like three times a year or twice a year... it's not very nice but back then I was fine with it because I wasn't very big, like but now I'd be like, "I'm not being weighed” [laughing].

Once again, it is important to note that Sally's recollection of school practices in relation to health and fitness were made after she had been out of school for one year. 
As part of the 'new health consciousness' (Tinning, 1991) the wider health and physical activity field is concerned with perpetuating the healthism discourse. The discourse's focus on the "fit and healthy” looking body and the individual responsibility and effort in achieving and maintaining this, serves to uphold and sustain the ever increasing commercial sector of the field including gyms, sporting and health clubs, exercise videos and television programmes, as well as sports and exercise specific clothing (Tinning, 1991). As part of the sport and physical activity field, school Physical Education programmes also have an interest in perpetuating the dominant healthism discourse out of their concern for the health of their students and to motivate participation in physical activities. Bourdieu (1991) suggested that the educational system works to perpetuate dominant discourses in order to build a common consciousness amongst the community.

The following data represents the relationship between a teacher's own beliefs, the PE subject matter, and the students’ discourses. The Greenvalley High School PE HoD, Mr Mason, linked body shape to fitness when describing the focus he was trying to portray through the physical fitness stream in the school's PE programme. Positively, he framed the point as being that,

...fitness does not necessarily mean being a physically fit looking being... [the programme] highlights to them [students] the range of ways you can go about maintaining a reasonable degree of physical fitness so that you're happy with your body and your body shape and size and that fitness doesn't mean looking like some of the images that you get on television....

The way that the Greenvalley High students spoke about health and fitness however, was in contrast with Mr Mason’s description. Despite his claim that fitness should not be linked to a thin, athletic body shape, Mr Mason saw his “job [as an PE teacher] getting bigger and bigger” as “obesity is becoming more and more prevalent”. He felt that obesity was a problem at Greenvalley High and that this was something of a concern for the school. 
Int.: Do you feel that with students at your school that there is a problem with obesity? Mr Mason: Yes, I think you'd be struggling to find a community that doesn't... it's still not an acceptable level. No, obesity even out here [rural area], too many kids are overweight, too many kids are I guess not healthy [sic] conscious which is something we try to change but as I mentioned earlier, it’s a tough job.

This provides an example of how obesity discourses can influence school PE practices and is consistent with other work reporting that PE teachers commonly used body weight as an indicator of health and fitness (Kirk and Colquhoun, 1989; Webb et al., 2008) who. From the young women’s perspectives on health and fitness, it appears as though this latter discourse about physical activity as a means of shaping the body and fighting obesity was more salient than the original one portrayed by Mr Mason which argued that fitness was not about an ideal body shape. Mr Mason’s own engagement with the healthism discourse was consistent with the school's practices of weighing students and fitness testing as part of the PE program. These experiences were significant particularly for some of the young women who specifically mentioned the weighing, running and sit-ups practices of their PE classes as the site for their learning about health and fitness. In this way the healthism discourse is perpetuated as the dominant discourse on the linguistic market therefore having a significant role in shaping the rural young women’s linguistic habitus in this field.

The young women's subordinate position was not experienced consciously as constraint; indeed none of them linked their feminine relation to the body as restricting their access to certain forms of physical activity. This form of complicity displayed by the young women is neither passive submission to external constraint nor a free adherence to values; it is inscribed through the habitus and becomes the unquestioning logic of practice (Bourdieu, 1991). There is however tension between reinforcing and challenging gender hierarchies in some of the young women's narratives. Tammy attempted to challenge the fit and healthy female body stereotype and Cassie's meanings of 
health and fitness included attention to the importance of work alongside body-related discourses. This would suggest that while there is a certain reproduction of the discourses which constrain young women, there is also room for agency.

\section{Conclusion}

The purpose of this paper was to explore the healthism discourse within the sport and physical activity field and particularly, how it is taken up by a sample of rural young women and perpetuated on the linguistic market through social reproduction and the habitus. The dominance and stability of the healthism discourse was prominent in the talk of the rural young women as they focussed on the body as a metaphor for health and adhered to a slim and not too muscular feminine ideal. Furthermore, participation in the types of activities that they considered health enhancing (sports and exercise) was at odds with their gendered habitus. Therefore, the physical capital gained from participating in physical activities held little currency due to the limited opportunity for exchange.

These findings may provide some insight into the current ineffectiveness of many interventions to increase physical activity among young people. The findings support McGannon and Mauws’s (2002) work which suggests that,

While people do have choice as to whether or not they exercise, their choices are not infinite. Instead, choices are limited by the discourses within which people (including themselves and others) are positioned when constructing who they are... (p. 77).

Thus, the long held notion that opportunities to maintain health are not equally available to all highlights the problem with the moral imperative and individual responsibility aspects underpinning 
the healthism discourse and most physical activity promotion initiatives. This may be particularly applicable to rural young people who are exposed to educational and global media messages around healthism, yet these run counter to their "choices”, both in terms of physical activity facilities and the expectations of their "lifestyle" in their gendered roles. This paper highlights the various ways that young people of different social and indeed, geographical locations negotiate universalised health discourses within their own life contexts. The restrictive impact of the healthism discourse is exacerbated for rural young women given their lack of formal sport/exercise options in small towns and the positioning of physical labour and farm work as 'men's work' rather than legitimate physical activity for women (see Lee \& Macdonald, 2009 for further discussion). Therefore, rural young women are further marginalised at the intersection of gendered rural discourses and the healthism discourse where they would be perceived as not taking responsibility for their own health by not participating in legitimised physical activities. Indeed, the rural young women themselves indicated this perspective in their interviews having bought into the healthism ideal.

We are therefore reminded, while rural young people are often labelled as “at risk" due to reported low levels of physical activity (Mummery, Schofield, Abt and Soper, 2000; Savage and Scott, 1998) and poor health and education outcomes (Haberkorn, Kelson, Tottenham and Magpantay, 2004; Strong, Tricket, Titulaer, and Bahia, 1998), that young people’s own accounts of their experiences in physical activity may be more complex than what is presented by large-scale, quantitative studies. Indeed, this paper and others (e.g. Lee and Abbott, 2009; Giddings and Yarwood, 2005; Leyshon, 2002) demonstrate that rural young people are shaped by their own “particular place of the possible” (Bourdieu, 1998, p.13) and do not see themselves as marginalised. Therefore, while we may be prompted within public health agendas to focus on certain health issues amongst this population, we need to remain aware of the social and cultural factors that shape rural young people’s approaches to health and fitness. For example, rather than labelling rural young people as marginalised because of lack of formal physical activity facilities, we could work towards 
legitimising physical recreation and physical labour within their understandings of "what counts" as physical activity. This may assist in making generic health promotion messages such as "Eat Well Be Active” more relevant to rural young people if they can recognise the types of opportunities they do have.

As demonstrated in previous research (e.g. Burrows et al., 2004; Evans, 2004; Rich, Holroyd \& Evans, 2004; Evans et al., 2008), the healthism discourse can promote unhealthy body practices and reinforce unsubstantiated claims around health and bodily appearance. Indeed, it was evident in the data presented that the rural young women often felt they did not live up to the dietary and physical activity standards of health and fitness that they believed to be ideal. The rural young women did not passively read obesity discourses they were exposed to throughout school but experienced them alongside constraints such as lack of formal physical activity facilities and discourses around the rural gender structure legitimising certain forms of physical activity and physical labour. It is a concern that these young people viewed themselves, particularly their bodies, as inadequate and falling short of the proper conduct they believed to be espoused by their school PE curriculum. While we are cautious not to dispute the relevance of a balanced diet and physical activity for longterm health outcomes, it appears that certain PE practices (e.g. weighing, fitness testing) can produce obstructive understandings of "what counts" as physical activity and healthy body shapes that continue into adulthood.

Importantly, in this paper it was demonstrated how the healthism discourse is perpetuated through schools. Given the longitudinal nature of this research, the dominance of school practices up to two years post-school remained evident in the young women's understandings of health and fitness. As such, it provides support for the growing number of researchers who are advocating a more critical approach to health and fitness in schools which may ultimately lead to a change in dominant discourses and culture. Such practices would emphasise flexible understandings of physical activity and health independent of body weight (i.e. one can be "overweight” as well as being fit and 
healthy) and challenge healthism discourse messages such as the body as a metaphor for health. Indeed, some agency in understandings of health and fitness were demonstrated by the rural young women providing evidence that there is scope for challenging the dominant healthism discourse. The necessary cultural and discursive environment for challenging the healthism discourse can be facilitated in schools through offering a critical approach as suggested above. While this process would be very long term, the habitus (as a structured, structuring structure) is a useful concept in understanding how behaviour change on a broad-scale can change culture. By critiquing healthism discourses in schools (habitus as structured), young people can then utilise this knowledge throughout their lives, and passing on to future generations through families and schools (habitus as structuring) messages that do not focus on the body as a metaphor for health. Furthermore, as Shilling (2004) theorises, the habitus and social meanings related to the body can be disrupted through self reflection. Presently, attention needs to be paid to the body and how young people perceive the relationship between health and the body. Interventions for rural young women should consider the salience of gendered discourses and promote physical activity for health and enjoyment rather than related to bodily appearance and weight loss. 


\section{References}

Aphramor, L. (2005) Is a weight-centred health framework salutogenic? Some thoughts on unhinging certain dietary ideologies, Social Theory \& Health, 3, 315-340.

Bourdieu, P. (1998) Practical reason: On the theory of action. California: Stanford University Press.

Bourdieu, P. (1991) Language and symbolic power (Cambridge, Polity Press).

Bourdieu, P. (1989) Social space and symbolic power, Sociological Theory, 7, 14-25.

Bourdieu, P. (1978) Sport and social class, Social Science Information, 17, 819-840.

Burns, R. (1993) Health, fitness and female subjectivity: What is happening in school health and physical education, in: L. Yates (Ed.) Feminism and education (Melbourne, La Trobe University Press).

Burrows, L., Wright, J. \& Jungersen-Smith, J. (2002) “Measure your belly”: New Zealand children's constructions of health and fitness, Journal of Teaching in Physical Education, 22, $39-48$.

Deutsher, C. \& Carr, D. (2000) Changing roles, Women in Sport Magazine, 6 (2), 34-36.

Evans, B. (2004) 'Be fit not fat': Broadening the childhood obesity debate beyond dualisms. Children’s Geographies, 2, 288-290.

Evans, J. \& Davies, B. (2004) Sociology, the body and health in a risk society, in: J. Evans, B. Davies \& J. Wright (Eds) Body knowledge and control: Studies in the sociology of physical education and health (London, Routledge).

Evans, J., Rich, E., Davies, B. \& Allwood, R. (2008) Education, disordered eating and obesity discourse (London, Routledge).

Gard, M. \& Wright, J. (2001) Managing uncertainty: Obesity discourses and Physical Education in a risk society, Studies in Philosophy of Education, 20, 535-549.

Giddings, R. and Yarwood, R. (2005). Growing up, going out and growing out of the countryside: Childhood experiences in rural England. Children's Geographies, 3, 101-114. 
Gorley, T., Holroyd, R. \& Kirk, D. (2003) Muscularity, the Habitus and the social construction of gender: Towards gender-relevant physical education, British Journal of Sociology of Education, 24, 429-448.

Haberkorn, G., Kelson, S., Tottenham, R. \& Magpantay, C. (2004) Country matters: Social atlas of rural and regional Australia (Canberra, Bureau of Rural Science).

Kirk, D. \& Colquhoun, D. (1989) Healthism and physical education, British Journal of Sociology of Education, 10, 417-434.

Lee, J. \& Abbott, R. (2009) Physical activity and rural young people’s sense of place. Children's Geographies, 7 (2), 191-208.

Lee, J. \& Macdonald, D. (2009) Rural young people and physical activity: Understanding participation through social theory, Sociology of Health and Illness, 31 (3).

Leyshon, M. (2002). On being 'in the field': Practice, progress and problems in research with young people in rural areas. Journal of Rural Studies, 18, 179-191.

Luke, A. (1997) Critical discourse analysis, in: L. J. Saha (Ed.) International Encyclopedia of the Sociology of Education (Oxford, Elsevier Science).

Luke, A. (1996) Text and discourse in education: An introduction to critical discourse analysis, in: M. W. Apple (Ed.) Review of Research in Education (Washington, DC, American Educational Research Association).

McGannon, K. R. \& Mauws, M. K. (2002) Exploring the exercise adherence problem: An integration of ethnomethodolgical and poststructuralist perspectives, Sociology of Sport Journal, 19, 67-89.

Monaghan, L. F. (2005) Discussion piece: A critical take on the obesity debate, Social Theory \& Health, 3, 302-314.

Mummery, W.K., Schofield, G.M., Abt, G., and Soper, L. (2000). Correlates of adolescent physical activity in regional Australia: Results from the Central Queensland Adolescent Physical 
Activity and Nutrition Study. Proceedings of the AIESEP World Sport Science Congress.

Rockhampton, Australia Central Queensland University, 3-14.

Rich, E. \& Evans, J. (2005) 'Fat ethics': The obesity discourse and body politics, Social Theory \& Health, 3, 341-358.

Rich, E., Holroyd, R. \& Evans, J. (2004) 'Hungry to be noticed': Young women, anorexia and schooling, in: J. Evans, B. Davies \& J. Wright (Eds) Body knowledge and control: Studies in the sociology of physical education and health (London, Routledge).

Savage, M.P. and Scott, L.B. (1998). Physical activity and rural middle school adolescents. Journal of Youth and Adolescence, 27, 245-253.

Shilling, C. (2003) The body and social theory (London, Sage).

Shilling, C. (2004) Physical capital and situated action: a new direction for corporeal sociology British Journal of Sociology of Education, 25, 473-487.

Strong, K., Trickett, P., Titulaer, I., \& Bhatia, K. (1998). Health in rural and remote Australia. Canberra: Australian Institute of Health and Welfare.

Taylor, S. (2000). Evaluating and applying discourse analytic research. In M. Wetherell, S. Taylor, \& S. Yates (Eds), Discourse as data: A guide for analysis (pp311-330). London: Sage. Tinning, R. (1991) Health Oriented Physical Education (HOPE): The case of physical education and the promotion of healthy lifestyles, The ACHPER National Journal, Summer, 4-10.

Webb, L., Quennerstedt, M. \& Ohman, M. (2008). Healthy bodies: construction of the body and health in physical education, Sport, Education \& Society, 13, 353-372.

Wright, J. \& Burrows, L. (2004) "Being healthy": The discursive construction of health in New Zealand children's responses to the National Education Monitoring Project, Discourse: Studies in the Cultural Politics of Education, 25, 211-230.

Wright, J., Macdonald, D. \& Groom, L. (2003) Physical activity and young people: Beyond participation, Sport, Education and Society, 8, 17-33.

Wright, J., O’Flynn, G. \& Macdonald, D. (2006) Being fit and looking healthy: Young women’s and men’s constructions of health and fitness, Sex Roles, 54, 707-716. 


\section{Figures}

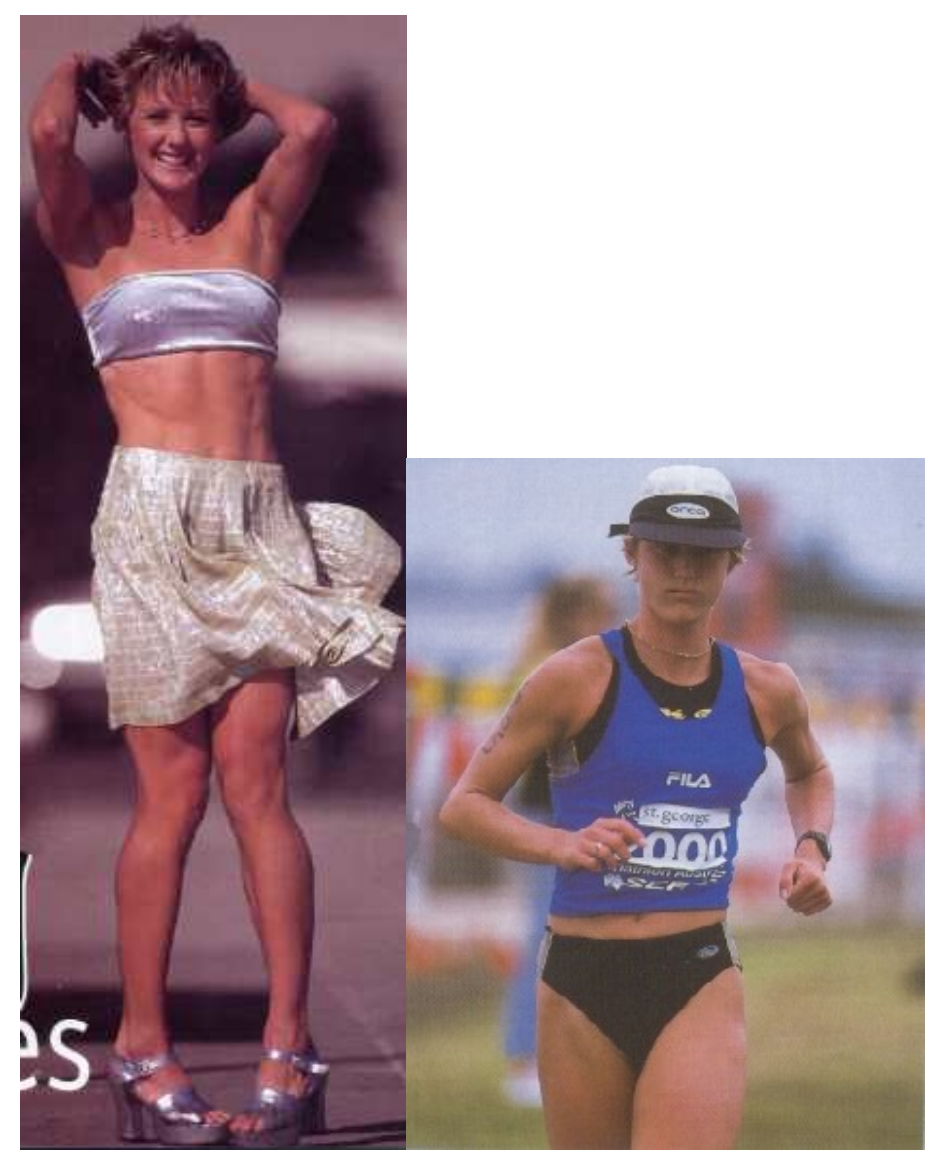

Figure 1 Pictures of a triathlete published in Women in Sport magazine (Deutsher \& Carr, 2000, reproduced with permission). 


\section{Footnote}

${ }^{1}$ The purpose of the LAP was to examine the place and meaning of physical activity in the context of young people's lives and in doing so, to investigate some of the taken for granted assumptions about young people's participation in physical activity and the relationship between physical activity and health that underpin practices in physical education and in public health promotion. For the national project, interview data were collected over a period of seven years (1999-2006) with a cohort of young people $(n=97)$ from various geographical and social locations in three states in eastern Australia. One-off interviews with a sample of parents and school Physical Education teachers were also conducted. 